\title{
A Brief Introduction of Skopos Theory
}

\author{
Xiaoyan $\mathrm{Du}$ \\ School of Foreign Languages, Qingdao University of Science and Technology Qingdao, China \\ Email: Devon_du@126.com
}

\begin{abstract}
There are many theories of translation study, among which, Skopos theory is a new branch and can explain and instruct many translation activities. This paper puts forth some basic concepts of Skopos theory, introduces some basic rules of it, and concludes the merits and limitations of Skopos theory.
\end{abstract}

Index Terms-Skopos theory, action, coherence, culture, adequacy, equivalence

\section{A Brief History of TRANSLATion StUdies AND the Definition of Skopos TheORY}

\section{A. A Brief History of Translation Studies}

Writings on the subject of translating go far back in recorded history. The practice of translation was discussed by, for example, Cicero and Horace (first century BCE) and St Jerome (fourth century CE). In St. Jerome's case, his approach to translating the Greek Septuagint Bible into Latin would affect later translations of the Scriptures. Indeed, the translation of the Bible was to be - for well over a thousand years and especially during the Reformation in the sixteenth century - the battleground of conflicting ideologies in Western Europe.

However, although the practice of translating is long established, the study of the field developed into an academic discipline only in the second half of the twentieth century. Before that, translation had normally been merely an element of language learning in modern language courses. The gearing of translation to language teaching and learning may partly explain why academia considered it to be of secondary status. Translation exercises were regarded as a means of learning a new language or of reading a foreign language text until one had the linguistic ability to read the original. Study of a work in translation was generally frowned upon once the student had acquired the necessary skills to read the original.

Another area in which translation became the subject of research was contrastive analysis. This is the study of two languages in contrast in an attempt to identify general and specific differences between them. It developed into a systematic area of research in the USA from the 1930s onwards and came to the fore in the 1960s and 1970s. Translations and translated examples provided much of the data in these studies. The contrastive approach heavily influenced other studies, which overtly stated their aim of assisting translation research. Although useful, contrastive analysis does not, however, incorporate sociocultural and pragmatic factors, nor the role of translation as a communicative act. Nevertheless, the continued application of a linguistic approach in general, and specific linguistic models such as generative grammar or functional grammar has demonstrated an inherent and gut link with translation. While, in some universities, translation continues to be studied as a module on applied linguistics courses, the evolving field of translation studies can point to its own systematic models that have incorporated other linguistic models and developed them for its own purposes. At the same time, the construction of the new discipline has involved moving away from considering translation as primarily connected to language teaching and learning. Instead, the new focus is the specific study of what happens in and around translating and translation.

The more systematic, and mostly linguistic-oriented, approach to the study of translation began to emerge in the 1950s and 1960s. There are a number of classic examples:

Jean-Paul Vinay and Jean Darbelnet: Stylistique comparee du francais de l'anglais, a contrastive approach that categorized what they saw happening in the practice of translation between French and English; Georges Mounin: Les problemes theoriques de la traduction, examined linguistic issues of translation;

Eugene Nida: incorporated elements of Chomsky's then fashionable generative grammar as a theoretical underpinning of his books, which were initially designed to be practical manuals for Bible translators.

These more systematic and "scientific" approaches in many ways began to mark out the territory of the academic investigation of translation. The word "science" was used by Nida in the title of his 1964 book (Toward a Science of Translating, 1964a, cited in Munday 2001). At that time, even the name of the emerging discipline remained to be determined, with candidates such as "translatology" in English - and its counterparts "translatologie" in French and "traductologia" in Spanish - staking their claim.

A seminal paper in the development of the field as a distinct discipline was James S. Holmes's The name and nature of translation studies. In his Contemporary Translation Theories, Gentzler (Munday, 2001) describes Holmes's paper as "generally accepted as the founding statement for the field". Crucially, Holmes puts forward an overall framework, describing what translation studies covers. This framework has subsequently been presented by the leading Israeli translation scholar Gideon Toury with a displaying map. The crucial role played by Holmes's paper is the delineation of the potential of translation studies. However, this paper omits any mention of the individuality of the style, 
decision-making processes and working practices of human translators involved in the translation process.

The surge in translation studies since the 1970s has seen different areas of Holmes's map come to the fore. Contrastive analysis has fallen by the wayside. The linguistic-oriented "science" of translation has continued strongly in Germany, but the concept of equivalence associated with it has declined. Germany has seen the rise of theories centered on text types and text purpose, while the Halliday views language as a communicative act in a sociocultural context, which has been prominent over the past decades, especially in Australia and the UK, and has been applied to translation in a series of works by scholars.

The late 1970s and the 1980s also saw the rise of a descriptive approach that had its origins in comparative literature and Russian Formalism. In literary polysystem, amongst other things, different literatures and genres, including translated and non-translated works, compete for dominance.

The 1990s saw the incorporation of new schools and concepts, with Canadian-based translation and gender research led by Sherry Simon, the Brazilian cannibalist school promoted by Else Vieira, postcolonial translation theory, with the prominent figures of the Bengali scholars Tejaswini Niranjana and Gayatri Spivak and, in the USA, the cultural-studies-oriented analysis of Lawrence Venuti, who champions the cause of the translator.

For years, the practice of translation was considered to be derivative and secondary, an attitude that inevitably devalued any academic study of the activity. Now, after much neglect and repression, translation studies have become well established. It is making swift advances worldwide, although not without a hint of trepidation.

\section{B. The Definition and History of Skopos Theory}

In the history of translation studies, for a long time, when people assess the quality of a translation, they are likely to employ "equivalence" or "faithfulness" to the source text as the most authoritative criterion to judge whether the translation is successful or not.

This kind of translation evaluation is stereotyped and over-simplified. Although this trend plays a positive role in guiding translation practice and standardizing the translation field, other factors should not be neglected, because translation is a complex human activity and the study of translation also should be descriptive. Under this situation, the Skopos theory, by viewing translation as an action with purpose, tries to open up a new perspective on such aspects as the status of the source text and the target text, their relationship, the concept of translation, the role of the translator, translation standards and strategies.

Skopos theory put forward by Hans J. Vermeer is the core of the functionalist translation theory developed in Germany in the 1970s. This is a new perspective of looking at translation, which is no longer limited by conventional source-text oriented views. Vermeer finds that, according to action theory, every action has a purpose, and, since translation is an action, it must have a purpose too. The purpose is assigned to every translation by means of commission.

To some extent, Skopos theory makes up for the deficiency of conventional translation theories. In the framework of Skopos theory, there are not such things as right or wrong, faithfulness or unfaithfulness, and the translation Skopos decides the translation process. Skopos theory accounts for different strategies in different situations, in which the source text is not the only factor involved.

Skopos is the Greek word for "aim" or "purpose" and was introduced into translation theory in the 1970s by Hans J. Vermeer as a technical term for the purpose of a translation and of the action of translating. Hans Vermeer believes that the purpose of a text determines the translation strategies. He objects to the traditional equivalence-based theories, which speak of the source text, or its effects on the source text reader, or the purpose of the source text author as a decisive factor in translation and raises the Skopos of the translation action to the center.

In Christiane Nord's Translating as a Purposeful Activity-Functionalist Approaches Explained, she defines the Skopos theory in this way:

Skopos is a Greek word for "purpose". According to Skopostheorie (the theory that applies the notion of Skopos to translation), the prime principle determining any translation process is the purpose (Skopos) of the overall translational action. This fits in with intentionality being part of the very definition of any action.

Skopos theory focuses above all on the purpose of the translation, which determines the translation methods and strategies that are to be employed in order to produce a functionally adequate result. This result is the TT, which Vermeer calls the translatum. Therefore, in Skopos theory, knowing why an ST is to be translated and what the function of the TT will be crucial for the translator.

The Skopos theory experienced four stages:

(1) Katharina Reiss and the functional category of translation criticism

(2) Hans J.Vermeer: Skopostheorie and beyond

(3) Justa Holz-Manttari and the theory of translational action.

(4) Christiane Nord's Function plus Loyalty Principle

The book Possibilities and Limits of Translation Criticism, written by Katharina Reiss, can be regarded as the "starting point for the scholarly analysis of translation in German" (Nord, 2001). In her opinion, the ideal translation would be one "in which the aim in the TL (target language) is equivalence as regards the conceptual content, linguistic form and communicative function of a SL (source language). However, she finds in some situation equivalence is impossible. She also explains some exceptions from the equivalence because of the translation brief which we will talk 
about next.

In order to bridge the gap between theory and practice, Hans J. Vermeer gives up the equivalence theory and lays the foundation of functional theory: Skopos theory. In his opinion, we can not solve all the problems in the translation just by linguistics alone. According to Action Theory, human action is a kind of purposeful behavior in a given situation. In his opinion, translation is a kind of translational action on the foundation of a source text. Therefore, Vermeer names his theory Skopos theory, a theory of purposeful action. Reader is one of the most important factors determining the purpose of the translation. Vermeer thinks that to translate means to produce a text in a target setting for a target purpose and target addressees in target circumstances.

"Translational action" was put forward by Justa Holz-Manttari in 1981. The theory is based on action theory, being designed to cover all forms of intercultural transfer. In his model, translation is defined as complex action designed to achieve a particular purpose. She pays much attention to the actionable aspects of the translational process. In the process, the role of the participants and the situational conditions in which their activities take place is analyzed. The generic term is "translational action". The purpose of translational action is to transfer message overcoming culture and language barriers through message transmitters produced by expects.

In her work Translating as a Purposeful Activity, Christiane Nord admits the merits of Vermeer's Skopos rule. However, in her book she also points out two interdependent shortcomings of the Skopos rule. One is that because of the differences in TT expectations, it is impossible for the translation purpose to satisfy all target readers. The other one is concerning the translator and the ST author. If the translation brief requires a translation whose communicative purposes are contrary to or incompatible with the intention of the original author, there would be no restriction to the range of possible ends. Considering these shortcomings, Nord puts forward the "loyalty principle" of Skopos theory: the responsibility of translators towards to their partners in translational interaction.

\section{BASIC CONCEPTS OF SKOPOS THEORY}

\section{A. Theory of Action}

The theory of action provides the foundation for Skopos theory.

Action is the process of acting, which means "intentionally (at will) bringing about or preventing a change in the world (in nature)" (Wright, 1968, p. 38, cited in Nord 2001). Action can thus be defined as an intentional "change or transition from one state of affaires to another" (Wright, 1968, p. 28, cited in Nord 2001). If there are two or more agents, the theory of action can become a theory of interaction.

Considering the multiple factors involved in a translation procedure, translation is also an interaction.

Translation theorists of the functionalist approaches view translating as a form of translational interaction, as intentional interaction, as interpersonal interaction, as communicative action, as intercultural action, and as text-processing action.

With emphasis on the interplay of each relation, such definition broadens the horizon of translation studies and helps to explain the complexity of translation.

\section{B. Skopos, Aim, Purpose, Intention, Function}

Skopos is a Greek word for 'purpose'. According to Skopostheorie, the prime principle determining any translation process is the purpose (Skopos) of the overall translational action. This fits in with intentionality being part of the very definition of any action. We can distinguish between three possible kinds of purpose in the field of translation: the general purpose aimed at by the translator in the translation process, the communicative purpose aimed at by the target text in the target situation, and the purpose aimed at by a particular translation strategy or procedure (Vermeer, 1989a, p.100, cited in Nord 2001). Nevertheless, the term Skopos usually refers to the purpose of the target text.

Apart from the term Skopos, Vermeer uses the related words aim, purpose, intention and function.

In order to avoid the conceptual confusion, Nord have proposed a basic distinction between intention and function (Nord, 2001). 'Intention' is defined from the viewpoint of the sender, who wants to achieve a certain purpose with the text. Yet the best of intentions do not guarantee a perfect result, particularly in cases where the situations of the sender and the receiver differ considerably. This distinction is particularly useful in translation, where the sender and receiver by definition belong to different cultural and situational settings. Because of this separation of sender and receiver, intention and function may have to be analyzed from two different angles (Nord, 2001).

Vermeer considers the teleological concepts aim, purpose, intention and function to be equivalent, subsuming them under the generic concept of Skopos.

The top-ranking rule for any translation is the 'Skopos rule', which says that a translational action is determined by its Skopos; that is, 'the end justifies the means' (Reiss and Vermeer, 1984, p.101, cited in Munday 2001). Vermeer explains the Skopos rule in the following way: Each text is produced for a given purpose and should serve this purpose. The Skopos rule thus reads as follows: translate/interpret/speak/write in a way that enables your text/translation to function in the situation in which it is used and with the people who want to use it and precisely in the way they want it to function.

\section{Intertextual and Intratextual Coherence}


Intratextual coherence specified that a translation should be acceptable in the sense that it is coherent with the receiver's situation, that is, the target-text receivers should be able to understand the target text and interpret it as being sufficiently coherent with their own communicative situation and culture. At the same time, we have to note that since the target text is produced according to the formation offered in the source text, it is expected to bear some kind of relationship with the source text. This relationship is what we call 'intertextual coherence' or 'fidelity'.

As in the case of the Skopos rule, the important point is that intertextural coherence should exist between source and target text, while the form it takes depends both on the translator's interpretation of the source text and on the translation Skopos(Nord, 2001).

Intertextual coherence is considered subordinate to intratextual coherence, and both are subordinate to the Skopos rule.

\section{Culture}

Vermeer's definition of culture focuses on norms and conventions as the main features of a culture. For him, a culture is the entire setting of norms and conventions as individual as a member of his society must know in order to be 'like everybody'-or to be able to be different from everybody (Vermeer, 1987a, p.28, cited in Nord 2001).

Translating means comparing cultures. Translators interpret source-culture phenomena in the light of their own culture-specific knowledge of that culture, from either the inside or the outside, depending on whether the translation is from or into the translator's native language-and-culture (Nord, 2001).

v. Adequacy and Equivalence

In the case of a translation, the translator is a real receiver of the source text who then proceeds to inform another audience, located in a situation under target-culture conditions, about the offer of information made by the source text. The translator offers this new audience a target text whose composition is guided by the translator's assumptions about their need, expectations, previous knowledge, and so on. These assumptions will be different from those made by the original author, because source-text addressees and target-text addressees belong to different cultures and language communities. This means the translator can not offer the same amount and kind of information as the source-text producer. What the translator does is to offer another kind of information in another form.

Within the framework of Skopostheorie, 'adequacy' refers to the qualities of a target text with regard to the translation brief: the translation should be adequate to the requirements of the brief. It is a dynamic concept related to the process of translational action and referring to the 'goal-oriented selection of signs that are considered appropriate for the communicative purpose defined in the translation assignment' (Reiss, 1989, p.163, cited in Nord 2001).

In Skopostheorie, equivalence means adequacy to a Skopos that requires that the target text serve the same communicative function or functions as the source text, thus preserving 'invariance of function between source and target text. This concept of equivalence is reduced to functional equivalence' on the text level of what Reiss refers to as 'communicative translation, not only from the perspective of word level.

For Reiss, the generic concept is adequacy, not equivalence. Equivalence may be one possible aim when translating but it is not held to be a translation principle valid once and for all.

\section{THE BASIC Rules OF SKOPOS THEORY}

Reiss and Vermeer aim at a general translation theory for all texts. They set out a detailed explanation of Vermeer's Skopos theory and adapts Reiss's functional text-type model to the general theory. There are six basic underlying "rules" of the theory (Reiss and Vermeer, 1984, p.119, cited in Munday 2001). These are:

1. A trunslatum (or TT) is determined by its Skopos.

2. A TT is an offer of information (Informationsangebot) in a target culture and TL concerning an offer of information in a source culture and SL.

3. A TT does not initiate an offer of information in a clearly reversible way.

4. A TT must be internally coherent.

5. A TT must be coherent with the ST.

6. The five rules above stand in hierarchical order, with the Skopos rule predominating.

Rule 2 is important in that it relates the ST and TT to their function in their respective linguistic and cultural contexts. The translator is once again (as was the case in Holz-Manttari's theory) the key player in a process of intercultural communication and production of the translatum. The irreversibility in point 3 indicates that the function of a translatum in its target culture is not necessarily the same as in the source culture. Rules 4 and 5 touch on general Skopos "rules" concerning how the success of the action and information transfer is to be judged: the coherence rule, linked to internal textual coherence, and the fidelity rule, linked to intertextual coherence with the ST.

The coherence rule states that the TT “must be interpretable as coherent with the TT receiver's situation" (Reiss and Vermeer, 1984, p.113, cited in Munday 2001). In other words, the TT must be translated in such a way that it is coherent for the TT receivers, given their circumstances and knowledge. The fidelity rule merely states that there must be coherence between the trunslatum and the ST or, more specifically, between:

a. the ST information received by the translator;

b. the interpretation the translator makes of this information; 
c. the information that is encoded for the TT receivers.

However, the hierarchical order of the rules means that intertextual coherence (rule 5) is of less importance than intratextual coherence (rule 4), which, in turn, is subordinate to the Skopos (rule 1). This down-playing (or "dethroning", as Vermeer terms it) of the status of the ST is a general fact of both Skopos and translational action theory.

\section{Merits, Discussions AND Limitations of SKopos Theory}

\section{A. Merits}

Skopos theory defines translating as an intentional, interpersonal, partly verbal intercultural interaction based on a source text. Skopos theory has brought a new concept for the status of the source text and target text. An important advantage of this theory is that it allows the possibility of the same text being translated in different ways according to the purpose of the target text and the commission which is given to the translator. In vermeer's words:

What the Skopos states is that one must translate, consciously and consistently, in accordance with some principle respecting the target text. The theory does not state what the principle is: this must be decided separately in each specific case. (Vermeer, 1989/2000, p.228, cited in Munday 2001)

The source text is just an "offer of information"; the target text becomes the focus. Thus translator can be released from restrictions to increase the range of possible translation strategies according to the different purposes the translator intends to achieve. Skopos theory has come to widen the narrow visions of traditional translation criticism, implying the acceptance of multiple versions and the evaluation of individual versions with respect to the purpose for which each version is intended. No source text has only one correct or perfect translation so the possibility of translation is expanded. Since Skopos theory puts forward a new criterion for translation "adequacy", translation is defined to be adequate or inadequate with regard to the purpose or the communicative function which is assigned to audience.

\section{B. Discussions}

There are also some criticisms of Skopos theory by other scholars, these include the following:

a. What purports to be a 'general' theory is in fact is only valid for nonliterary texts. Literary texts are considered either to have no specific purpose and/or to be far more complex stylistically.

b. Reiss's text type approach and Vermeer's Skopos theory are in fact considering different functional phenomena and cannot be lumped together.

c. Skopos theory does not pay sufficient attention to the linguistic nature of the ST nor to the reproduction of microlevel features in the TT. Even if the Skopos is adequately fulfilled, it may be inadequate at the stylistic or semantic levels of individual segments.

Vermeer answers the first point above by stressing that goals, purposes, functions and intentions are 'attributed to 'actions. Thus, a writer of a poem may have goals of having the resultant translatum (poem) published and of keeping copyright over it so as to make money from its reproduction. He or she may also have the intention of creating something that exists for itself ('art for art's sake')

Two points are at issue in the second criticism: to what extent does ST type determine translation method and what is the logic of the link between ST type and translation Skopos. The third criticism in particular is tackled by another functionalist, Christiane Nord, with her model of translation-oriented text analysis.

\section{Limitations}

Like any other theories, Skopos theory is also not perfect. According to Nord, there are two interdependent limitations of this theory. One concerns the culture-specificity of translational models; the other has to do with the relationship between the translator and the source-text author.

To solve the above problem, Nord introduces the loyalty principle into the functionalist model. In Nord's terms, function refers to the factors that make a target text work in the intended way in the target situation. Loyalty refers to the interpersonal relationship between the translator, the source-text sender, the target-text addressees and the initiator. (Nord, 2001). The combination of function and loyalty is the successful point of Nord's functionalist approach, and are respectively the two pillars of her approach which also answers many scholars criticism of Skopos theory.

\section{REFERENCES}

[1] Nord, C. (2001). Translating As a Purposeful Activity, Functionalist Approaches Explained. Shanghai: Shanghai Foreign Language Education Press.

[2] Munday, J. (2001). Introducing Translation Studies, theories and applications. London: London and New York.

[3] Lefevere, A. (1992). Translation, Rewriting and the Manipulation of Literary Fame. London \& New York: Routledge.

[4] Halliday, M. A. K. (2000). An Introduction to Functional Grammar. Beijing: Foreign Language Teaching and Research Press.

Xiaoyan Du was born in Weifang, China in 1976. She received her M.A. degree in linguistics from Ocean University of China in 2010.

She is currently a lecturer in the School of Foreign Languages, Qingdao University of Science and Technology, Qingdao, China. Her research interests include translation studies and second language acquisition. 